\title{
Optimization of the Physical and Mechanical Properties of a Spline Surface Fabricated by High-Speed Cold Roll Beating Based on Taguchi Theory
}

\author{
Fengkui Cui, ${ }^{1,2}$ Yongxiang Su $\mathbb{D}^{1,2}$ Shaoke Xu, ${ }^{1,2}$ Fei Liu $\mathbb{D}^{1,2}$ and Guolin Yao ${ }^{1,2}$ \\ ${ }^{1}$ School of Mechatronics Engineering, Henan University of Science and Technology, Luoyang, Henan 471003, China \\ ${ }^{2}$ Collaborative Innovation Center of Machinery Equipment Advanced Manufacturing of Henan Province, Luoyang, \\ Henan 471003, China
}

Correspondence should be addressed to Yongxiang Su; syxsuper@163.com

Received 21 November 2017; Revised 7 January 2018; Accepted 15 January 2018; Published 11 February 2018

Academic Editor: Yannis Dimakopoulos

Copyright @ 2018 Fengkui Cui et al. This is an open access article distributed under the Creative Commons Attribution License, which permits unrestricted use, distribution, and reproduction in any medium, provided the original work is properly cited.

\begin{abstract}
The aim of this work is to control the physical and mechanical properties of a spline surface and achieve a reasonable choice of high-speed cold roll-beating processing parameters. The surface residual stress and surface work hardening at the indexing circle serve as the main evaluation indices of the physical and mechanical properties of the spline surface. The influence degree of the processing parameters on each evaluation index is analyzed using Taguchi theory. An optimized model for improving the Taguchi process capability index that combines Taguchi theory with entropy theory is established, and the integral process capacity index is optimized via the generalized price reduction gradient method. The results of the optimization and the verification test are implemented in a high-speed cold roll forming test for comparison. The results show that the influence of processing parameters on the physical and mechanical properties of the splash surface of the cold roll can be ordered as follows: feed rate > roll round radius $>$ cold roll-beating speed. In addition, the spline surface physical and mechanical properties of the optimal processing parameters were obtained for the combination of a cold rolling speed of $1581 \mathrm{r} / \mathrm{mm}$, feed rate of $42 \mathrm{~mm} / \mathrm{min}$, and roll round radius of $2 \mathrm{~mm}$.
\end{abstract}

\section{Introduction}

High-speed cold roll-beating forming is a high-efficiency, high-quality, green, plastic forming technology that is widely used in aerospace applications, automotive applications, machine tool fabrication, and other types of manufacture of industrial experimental parts [1-3]. Cold roll beating is a complex forming process influenced by multiple factors. The forming process is implemented under nonuniform thermodynamic coupling of high stress and large deformation and results in a certain degree of work hardening and residual stress in the workpiece surface. Of the cold rolling processing parameters involved in the forming process of stress application, deformation has the strongest influence and is associated with changes in the physical and mechanical properties of the workpiece surface. However, in the actual production and processing phases, the scientific problems that urgently need solutions are how to weigh the influence of the process parameters on the physical and mechanical properties of the surface of the cold roll spline and how to control the surface physical and mechanical performance to enhance the use of cold rolling parts. Therefore, identifying the influence of the cold rolling process parameters on the spline surface hardening and residual stress and determining the reasonable processing parameters of surface hardening and residual stress to control the surface physical and mechanical properties are of great scientific significance and engineering application value regarding the improvement of the physical and mechanical properties of the cold rollbeating spline surface.

In the context of cold roll forming technology, Kurz established a finite element simulation model to study the interaction between the metal plastic deformation field and stress field during cold roll-beating forming and calculated the key parameters of the cold roll-beating plastic forming process, including the metal workpiece strain and stress size [4]. 
TABLE 1: Chemical composition of the 20 steel (mass fraction, \%).

\begin{tabular}{lcccccr}
\hline Carbon & Silicon & Manganese & Phosphorus & Sulfur & Nickel & Chromium \\
\hline 0.20 & $0.17-0.37$ & $0.35-0.65$ & $\leq 0.035$ & $\leq 0.035$ & $\leq 0.30$ & $\leq 0.25$ \\
\hline
\end{tabular}

Mingshun et al. improved the cold roll-beating forming principle by introducing an analytical formula to obtain the deformation force using the principal stress method and then using Abaqus to establish a high-speed cold rollbeating simulation, analyzing the variation law of deformation force and the influence law of process parameters on the deformation force and further analyzing the influence of the process parameters on the surface properties of a cold roll-beating workpiece $[5,6]$. Cui et al. performed simulated cold rolling experiments and scanning electron microscopy at room temperature and studied the dislocation mechanism and the work-hardening rate of 20 steel; they identified the relationships between the dislocation density and the strain and between the work-hardening rate and the dislocation density [7]. Yan et al. established a cold rollbeating screw numerical simulation program and analyzed the microstructure deformation, hardness distribution, and hardened layer distribution of the screw through the analysis of stress field and strain field numerical simulation results and screw cold roll-beating forming test results; in addition, numerical simulations and experiments were combined to study the metal flow law in the process of screw cold rolling [8]. Ding et al. improved the surface performance of cold rollbeating forming splines and studied the influence of cold rollbeating forming parameters on the distribution of residual stress and the depth distribution of the residual compressive stress in the tooth root, index circle, and tooth tip of a spline tooth profile by measuring the distribution of residual stress at the splitting circle of the cold roll-beating spline via the contour method [9].

In the application of Taguchi theory, to study the effect of the inclination angle, axial depth of cutting, spindle speed, and feed rate on the surface integrity of the workpiece during the milling process of the titanium coated carbide ball mill, Masmiati and Sarhan used the Taguchi optimization method to determine the degree of impact on the surface integrity of the workpiece, and the control parameters were determined with minimal variability; the results showed that the optimization results can improve the residual stress and microhardness in the inclined end milling process [10]. To study the surface roughness of glass fiber plastic processed with diamond (PCD), Palanikumar selected the cutting speed, feed speed, and cutting depth for the cutting parameters and analyzed the influence of these parameters on the surface roughness using a Taguchi test design to determine the optimal cutting conditions for minimizing the surface roughness [11]. Rupajati et al. used the fuzzy logic of the Taguchi method on the wire-cutting process to optimize the casting layer thickness and the surface roughness simultaneously. By transforming the optimization of complex multiperformance characteristics into the optimization of a single response performance index, they found that a combination of the Taguchi method and fuzzy logic in the wire-cutting process effectively improves the wire-cutting process performance [12]. Chen et al. used the Taguchi method and multiobjective quantum-behavior particle swarm optimization to optimize the surface roughness of 7075-T6 aluminum alloy in end milling. First, they used Taguchi orthogonal arrays and variance analysis to determine the critical factors of surface roughness; they then used the response surface method to construct a surface roughness prediction model; finally, they used a multiobjective quantum-behavior particle swarm optimization algorithm to optimize the surface roughness. The results showed that the surface roughness produced using the algorithm is better than the surface roughness under nonoptimal conditions [13].

In view of the above background, scholars have performed substantial research on the physical and mechanical properties of the surface of a cold roll-beating forming workpiece from the aspects of stress and strain, metal flow, and microstructure evolution. In addition, many scholars have cited Taguchi theory in the field of technical processing for workpiece surface performance prediction and optimization. However, there have been few studies on the optimization of cold roll-beating forming in the actual research process; in particular, the application of Taguchi method optimization to the physical and mechanical properties of the spline surface of high-speed cold roll beating has not been reported. Therefore, in this study, the experimental results of spline cold rolling are used to calculate the influence degrees of the forming parameters on the physical and mechanical properties of a spline surface using the Taguchi method. In addition, entropy theory is used to improve the Taguchi process capability index, establishing an optimized model for improving the index function of the Taguchi process. Moreover, the generalized step-down gradient method is used to optimize the overall process capability index to obtain the appropriate processing parameters to optimize the physical and mechanical properties of a high-speed cold rollbeating spline surface. Through the study of the cold rollbeating forming test and using Taguchi theory, the control of surface hardening and residual stress and the selection of cold rolling parameters in the splicing cold forming process are realized to improve the physical mechanics of the spline surface performance.

\section{Forming Experiment of a Spline under High-Speed Cold Roll Beating}

2.1. Experimental Materials. The blank material of the spline cold roll-beating experiment is 20 steel, whose main chemical composition is shown in Table 1 . After a normalizing treatment at $910^{\circ} \mathrm{C}$, the yield strength is $245 \mathrm{MPa}$, the elastic modulus is $206 \mathrm{GPa}$, and the tensile strength is $410 \mathrm{MPa}$. The formed spline is an involute spline. The spline has the following properties: the modulus is 2.5 , the pressure angle is 30 degrees, and the number of teeth is 14 . 
TABLE 2: Factor level table.

\begin{tabular}{lccc}
\hline Experimental level & & $\begin{array}{c}\text { Experimental factors } \\
\text { Ceed rate, } f(\mathrm{~mm} / \mathrm{min})\end{array}$ & Fillet radius of hobbing wheel, $r(\mathrm{~mm})$ \\
\hline 1 & 1428 & 21 & 1 \\
2 & 1581 & 28 & 1.5 \\
3 & 1806 & 35 & 2 \\
4 & 2032 & 42 & 2.5 \\
5 & 2258 & 51 & 3 \\
\hline
\end{tabular}

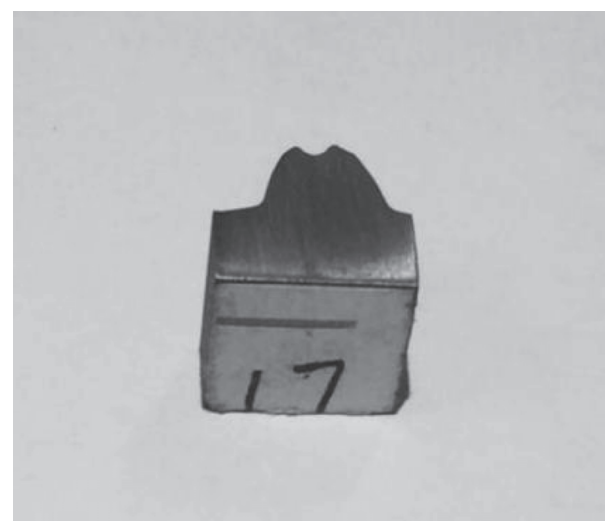

Figure 1: The spline specimen.

2.2. Experimental Equipment. The cold roll-beating process of the involute spline was conducted on a Swiss Grob ZRm 9 roller. The surface hardness was measured using an HVS$1000 \mathrm{~N}$ microhardness instrument. The Serein-CMM FUNCTION 1000 three-coordinate measuring instrument was used to measure the residual stress of the profile method. The grain size change of the spline tooth surface was observed using a JSM-5610LV scanning electron microscope. The spline tooth was cut using an sf-40jc low-speed wire-cutting electrical discharge machine.

2.3. Experimental Procedures. The cold roll-beating process of the involute spline was performed on the roller by pulling out the way. A segment of the spline gear was cut using a linear cutting machine, as shown in Figure 1. After grinding and polishing the spline tooth specimen, the Victorinox hardness in the circular specimen was measured using the HVS-1000N microhardness tester normal to the surface from the outside to the interior. Three points were measured on this part. The distance between each measuring point was $0.2 \mathrm{~mm}$. The load was $1 \mathrm{~N}$ at each measurement, and the loading time was $10 \mathrm{~s}$.

In the WEDM-LS procedure, using a $0.1 \mathrm{~mm}$ bronze wire, a tooth is cut off from the spline at the speed of $2 \mathrm{~mm} / \mathrm{min}$, and then the specimen is cut along the symmetrical surface shown in the shaded part of Figure 2(a) at a feed rate of $0.5 \mathrm{~mm} / \mathrm{min}$. The dimensions of each specimen are as follows: $l=10 \mathrm{~mm}, w=4.35 \mathrm{~mm}$, and $h_{0}=2.68 \mathrm{~mm}$. The point coordinates of the cutting plane of Figure 2(a) were measured using a Serein-CMM FUNCTION 1000 threecoordinate measuring machine (to reduce the error, both surfaces produced by cutting must be measured, and a total of four surfaces must be measured). The measurement was performed at $0.01 \times 0.01 \mathrm{~mm}$ intervals using the reciprocating measurement method (a single measurement track along the direction parallel to the cutting line is required to cover the two surfaces). As the annealed samples can be considered to not contain residual stress, when the cutting is done, any form of deformation of the unannealed specimen relative to the corresponding position of the annealed specimen can be attributed to the release of residual stress. After measurement, the measured data that correspond to the two planes are subtracted to obtain the measured point change amount (vector deformation). This is the amount of deformation caused by the release of the residual stress of the specimen. A curved surface regarding the small change (an annealed specimen relative to the one that was not) corresponding to each measured point is fitted using the three-order spline fitting algorithm. Then, the surface was inverted and taken as a boundary condition to be applied to the finite element model, which had the same size and shape as the deformed specimen, using Abaqus software. The material model taken in the simulation analysis was a static stress-strain one, which was established using quasi-static compression tests on 20 steel on the experiment platform. Then, finite element static solution is performed in Abaqus software; the deformed model is restored to the shape before cutting. In order to avoid the rigid body displacement in the model analysis process, an additional constraint that does not affect the free deformation of the contour is imposed on the corner node at the other end of the model, consistent with the literature [14-16]. Finally, the stress on the cut surface of the model obtained after the solution is obtained is equivalent to the residual stress at the same position when the sample is not cut. The extraction direction and position are shown in Figure 2(b). The residual stress at the spline circle is extracted by the position and direction of $b$, and the extraction node spacing is about $0.05 \mathrm{~mm}$ (there is some distortion so it is not possible to select nodes with strict regular spacing), where $h_{a}=2.20 \mathrm{~mm}, h_{d}=$ $1.39 \mathrm{~mm}$, and $h_{f}=0.5 \mathrm{~mm}$.

2.4. Orthogonal Experimental Design for the Cold Roll-Beating Spline. In the experiment of the spline formed by cold roll beating, the cold roll-beating speed, feed speed, and fillet radius of the hobbing wheel have an important influence on the surface residual stress and the work-hardening degree of the cold roll-beating spline surface. Therefore, the three parameters are chosen as the research factors. Experiments are conducted using a three-factor and five-level L25 orthogonal array table, as shown in Table 2. 


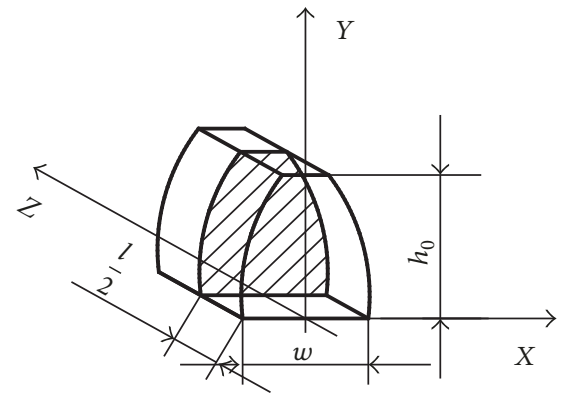

(a) The shape of a specimen and the measurement section of the cutting position

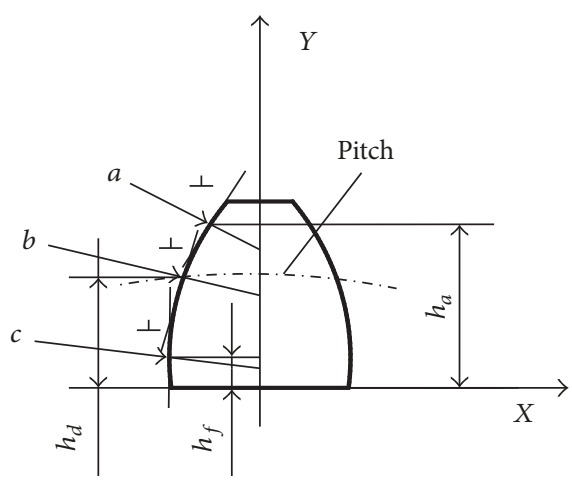

(b) Position and direction of residual stress extraction

FIGURE 2: Measurement scheme of residual stress using the contour method.

TABLE 3: Experimental results for the cold roll-beating spline.

\begin{tabular}{|c|c|c|c|c|c|c|c|c|c|c|c|}
\hline \multirow{2}{*}{$\begin{array}{l}\text { Experiment } \\
\text { serial number }\end{array}$} & \multicolumn{3}{|c|}{ Processing parameters } & \multicolumn{4}{|c|}{$\begin{array}{c}\text { Degree of work hardening, } \\
\qquad H_{v}(\%)\end{array}$} & \multicolumn{4}{|c|}{$\begin{array}{l}\text { Residual stress, } \\
\delta(\mathrm{MPa})\end{array}$} \\
\hline & $n$ & $f$ & $r$ & $\begin{array}{c}\text { Test } \\
\text { point } 1\end{array}$ & $\begin{array}{c}\text { Test } \\
\text { point } 2\end{array}$ & $\begin{array}{c}\text { Test } \\
\text { point } 3\end{array}$ & $\begin{array}{l}\text { Average } \\
\text { value }\end{array}$ & $\begin{array}{c}\text { Test } \\
\text { point } 1\end{array}$ & $\begin{array}{c}\text { Test } \\
\text { point } 2\end{array}$ & $\begin{array}{c}\text { Test } \\
\text { point } 3\end{array}$ & $\begin{array}{c}\text { Average } \\
\text { value }\end{array}$ \\
\hline 1 & 1 & 1 & 1 & 140.97 & 140.95 & 140.96 & 140.96 & -67.38 & -67.44 & -47.44 & -67.42 \\
\hline 2 & 1 & 2 & 2 & 143.32 & 143.36 & 143.37 & 143.35 & -72.73 & -72.66 & -72.71 & -72.7 \\
\hline 3 & 1 & 3 & 3 & 147.58 & 147.65 & 147.66 & 147.63 & -79.37 & -79.38 & -79.39 & -79.38 \\
\hline 4 & 1 & 4 & 4 & 148.65 & 148.74 & 148.74 & 148.71 & -82.99 & -83.01 & -83.03 & -83.01 \\
\hline 5 & 1 & 5 & 5 & 149.05 & 149.09 & 149.07 & 149.07 & -87.09 & -87.13 & -87.11 & -87.11 \\
\hline 6 & 2 & 1 & 2 & 140.22 & 140.28 & 140.25 & 140.25 & -68.77 & -68.73 & -68.78 & -68.76 \\
\hline 7 & 2 & 2 & 3 & 142.49 & 142.51 & 142.44 & 142.48 & -75.14 & -75.17 & -75.17 & -75.16 \\
\hline 8 & 2 & 3 & 4 & 146.35 & 146.27 & 146.34 & 146.32 & -78.8 & -78.76 & -78.81 & -78.79 \\
\hline 9 & 2 & 4 & 5 & 147.39 & 147.41 & 147.43 & 147.41 & -83.03 & -83.05 & -83.04 & -83.04 \\
\hline 10 & 2 & 5 & 1 & 148.09 & 148.11 & 148.07 & 148.09 & -87.08 & -87.04 & -87.09 & -87.07 \\
\hline 11 & 3 & 1 & 3 & 140.84 & 140.89 & 140.88 & 140.87 & -72.14 & -72.13 & -72.18 & -72.15 \\
\hline 12 & 3 & 2 & 4 & 141.94 & 141.88 & 141.94 & 141.92 & -49.49 & -79.52 & -79.46 & -79.49 \\
\hline 13 & 3 & 3 & 5 & 145.88 & 145.94 & 145.94 & 145.92 & -84.79 & -84.85 & -84.85 & -84.83 \\
\hline 14 & 3 & 4 & 1 & 146.75 & 146.79 & 146.81 & 146.78 & -88.04 & -88.01 & -88.04 & -88.03 \\
\hline 15 & 3 & 5 & 2 & 148.5 & 147.5 & 148 & 148 & -73.07 & -73.03 & -73.02 & -73.04 \\
\hline 16 & 4 & 1 & 4 & 139.85 & 139.89 & 139.84 & 139.86 & -79.01 & -79.05 & -79.06 & -79.04 \\
\hline 17 & 4 & 2 & 5 & 142.01 & 142.03 & 142.02 & 142.02 & -82.74 & -82.78 & -82.79 & -82.77 \\
\hline 18 & 4 & 3 & 1 & 145.75 & 145.83 & 145.85 & 145.81 & -84.65 & -84.59 & -84.65 & -84.63 \\
\hline 19 & 4 & 4 & 2 & 147.68 & 147.73 & 147.75 & 147.72 & -87.94 & -87.94 & -87.91 & -87.93 \\
\hline 20 & 4 & 5 & 3 & 149.04 & 149.01 & 149.01 & 149.02 & -74.78 & -74.76 & -74.71 & -74.75 \\
\hline 21 & 5 & 1 & 5 & 139.66 & 139.75 & 139.75 & 139.72 & -78.57 & -78.62 & -78.55 & -78.58 \\
\hline 22 & 5 & 2 & 1 & 142.32 & 142.38 & 142.41 & 142.37 & -83.19 & -83.28 & -83.28 & -83.25 \\
\hline 23 & 5 & 3 & 2 & 146.17 & 146.22 & 146.21 & 146.2 & -83.28 & -83.26 & -83.21 & -83.25 \\
\hline 24 & 5 & 4 & 3 & 148.21 & 148.21 & 148.25 & 148.23 & -84.83 & -84.88 & -84.9 & -84.87 \\
\hline 25 & 5 & 5 & 4 & 148.86 & 148.89 & 148.89 & 148.88 & -88.22 & -88.26 & -88.15 & -88.21 \\
\hline
\end{tabular}

2.5. Experimental Results for the Cold Roll-Beating Spline. For each cold roll-beating spline specimen, the work-hardening degree and the residual stress of 3 points are measured at the graduation circle. According to (1), the average measured value $\left(R^{*}\right)$ for each specimen is calculated with its measured value. The experimental results are shown in Table 3.

$$
R_{i}^{*}=\sum_{j=1}^{Q} \frac{R_{i j}}{Q} .
$$


TABLE 4: Signal-to-noise ratio of the cold roll-beating spline experimental results.

\begin{tabular}{|c|c|c|c|}
\hline Experiment serial number & $\begin{array}{c}\text { Signal-to-noise ratio of } \\
\text { work-hardening degree, } H_{\mathrm{S} / \mathrm{N}}(\mathrm{dB})\end{array}$ & $\begin{array}{c}\text { Residual stress } \\
\text { signal-to-noise ratio, } \delta_{\mathrm{S} / \mathrm{N}}(\mathrm{dB})\end{array}$ & $Z_{\mathrm{S} / \mathrm{N}}(\mathrm{dB})$ \\
\hline 1 & 42.982 & 36.576 & 39.779 \\
\hline 2 & 43.128 & 37.231 & 40.180 \\
\hline 3 & 43.383 & 37.994 & 40.689 \\
\hline 4 & 43.447 & 38.383 & 40.915 \\
\hline 5 & 43.468 & 38.801 & 41.135 \\
\hline 6 & 42.938 & 36.747 & 39.843 \\
\hline 7 & 43.075 & 37.520 & 40.298 \\
\hline 8 & 43.306 & 37.929 & 40.618 \\
\hline 9 & 43.371 & 38.386 & 40.879 \\
\hline 10 & 43.411 & 38.797 & 41.104 \\
\hline 11 & 42.976 & 37.165 & 40.071 \\
\hline 12 & 43.041 & 38.006 & 40.524 \\
\hline 13 & 43.282 & 38.571 & 40.927 \\
\hline 14 & 43.333 & 38.893 & 41.113 \\
\hline 15 & 43.405 & 37.271 & 40.338 \\
\hline 16 & 42.914 & 37.957 & 40.436 \\
\hline 17 & 43.047 & 38.357 & 40.702 \\
\hline 18 & 43.276 & 38.550 & 40.913 \\
\hline 19 & 43.389 & 38.883 & 41.136 \\
\hline 20 & 43.465 & 37.472 & 40.469 \\
\hline 21 & 42.905 & 37.906 & 40.406 \\
\hline 22 & 43.068 & 38.408 & 40.738 \\
\hline 23 & 43.299 & 38.408 & 40.854 \\
\hline 24 & 43.419 & 38.575 & 40.997 \\
\hline 25 & 43.457 & 38.910 & 41.184 \\
\hline
\end{tabular}

In the equation, $i$ is the experimental serial number and $Q$ is the number of experimental test points $(Q=3)$.

2.6. Analysis of the Experimental Results for the Cold RollBeating Spline. The signal-to-noise ratio $(\mathrm{S} / \mathrm{N})$ is the parameter that describes the relationship between active ingredients and components. Therefore, the Taguchi method uses this ratio as the evaluation feature of the optimization design and analysis of the physical and mechanical properties of the cold roll-beating spline surface to study the influence degree of the machining parameters on the mechanical surface properties of the cold roll-beating spline [17-19]. Because the cold roll-beating hardening process can significantly improve the surface strength of the spline, under external force, plastic deformation occurs when the local spline stress exceeds the yield limit of the material. Because work hardening limits the continuous development of plastic deformation, the safety of splines and fittings can be improved. The cold rollbeating spline experimental results show that the spline tooth surface residual stress is compressive. The increase of residual compressive stress can reduce the expansion of microcracks on the spline surface and improve the fatigue strength of the spline. Therefore, the degree of work hardening and residual stress is characterized by the-larger-the-better characteristic given by (2). The processing results are shown in Table 4.

The signal-to-noise ratio $(\mathrm{dB})$ of the-larger-the-better characteristic is expressed as follows:

$$
\frac{S}{N_{i}}=-10 \lg \left(\frac{1}{r} \sum_{i=1}^{r} \frac{1}{R_{i}^{2}}\right) .
$$

In order to further explore the influence degree of the large objective function, ANOVA was used to analyze the degree of difference of each design variable. The total difference is equal to the sum of squared deviations (SS) and the sum of the deviations of cold roll-beating speed, feed speed, and rolling wheel fillet radius, as given by (3)-(4). The difference between the different processing parameters in the spline cold roll-beating test is calculated by the sum of the average deviations of the average result of cold roll-beating test according to (5). The formula for calculating the degree of freedom of each factor is as shown in (6), and the degree 
TABLE 5: The table of variance data analysis.

\begin{tabular}{lccccc}
\hline & SS & Degrees of freedom, $f$ & Mean square, $v$ & Statistics, $F$ & Contribution rate, $p$ \\
\hline Cold roll-beating speed, $n$ & 0.166 & 4 & 0.0415 & 4.61 & $7.49 \%$ \\
Feed rate, $f$ & 1.963 & 4 & 0.4907 & 54.52 & $80.69 \%$ \\
Fillet radius of the hobbing wheel, $r$ & 0.223 & 4 & 0.0558 & 6.2 & $11.83 \%$ \\
Unknown factor, $e$ & 0.036 & 3 & 0.009 & $/$ & $/$ \\
Sum & 2.388 & $/$ & $/$ & $/$ & $100 \%$ \\
\hline
\end{tabular}

of freedom error is calculated using (7). The analysis results of the variation are shown in Table 5.

$$
\begin{aligned}
\mathrm{SS}_{T} & =\mathrm{SS}_{n}+\mathrm{SS}_{f}+\mathrm{SS}_{r}+\mathrm{SS}_{e} \\
\mathrm{SS}_{T} & =\sum_{i=1}^{n} y_{i}^{2}-\frac{G^{2}}{N} \\
\mathrm{SS}_{L} & =\sum_{j=1}^{t} \frac{S y_{i}^{2}}{t}-\frac{G^{2}}{N} \\
f_{T} & =j-1 \\
f_{e} & =f_{T}-f_{n}-f_{f}-f_{r} .
\end{aligned}
$$

Among the parameters in the equations, $\mathrm{SS}_{T}, \mathrm{SS}_{n}, \mathrm{SS}_{f}$, $\mathrm{SS}_{r}$, and $\mathrm{SS}_{e}$ are the total difference of all parameters, the difference of cold roll-beating speed, the difference of feed speed, the difference of round radius of rolling wheel, and the difference of unknown factors, respectively. $y_{i}$ is the comprehensive signal-to-noise ratio for each spline cold rollbeating test, $G$ is the sum of the comprehensive signal-tonoise ratios of each test result, $N$ is the total number of experiments $(N=25), S y_{i}^{2}$ is the sum of all $y_{i}$ under each parameter $L, j$ is the horizontal quantity of the processing parameter $L$, and $t$ is the number of repetitions at each level of the processing parameter. $f_{T}, f_{n}, f_{f}, f_{r}$, and $f_{e}$ are the total degrees of freedom of all parameters, the degree of freedom of cold roll-beating speed, the degree of freedom of feed speed, the degree of freedom of round radius of rolling wheel, and the degree of freedom of unknown factors, respectively.

The coefficient of variation analysis shows that a higher contribution rate $(p=80.69 \%)$ corresponds to a greater impact. Thus, Table 5 indicates that the influence of feed speed (contribution rate $p=80.69 \%$ ) on the physical and mechanical properties of cold roll-beating spline surface is the most significant. The round corner radius (contribution rate $p=11.83 \%$ ) is the second most significant, and the cold roll-beating speed has the least impact (contribution rate $p=7.49 \%)$.

\section{Optimization Analysis of the Physical and Mechanical Properties of Cold Roll-Beating Spline Surfaces}

According to the literature $[20,21]$, the test results of the cold rolling test are combined with the analysis of variance and the test of variance homogeneity. The influence of the three factors on the rotational speed of cold rolling, the feed rate, and fillet radius of hobbing wheel and the interaction of its two orders are studied. And they are analyzed by Pareto diagram and two-order interaction factor diagram, from which it can be concluded that there is no interaction between the round radius of roll wheel and cold rolling speed and feed rate. The interaction between the cold rolling speed and the feed rate is weak. Therefore, it is determined that the rotational speed of the cold rolling, the feed rate, and the radius of the round angle of the rolling wheel are the design variables. Work hardening and residual stress are used as the optimization objective. The mathematical optimization algorithm is used to establish the mathematical relationship between the design variables and the optimization targets.

The Taguchi method can effectively optimize multiparameter or multitarget machining systems and has the characteristics of simple realization, fast convergence, and global optimization [22-24]. However, in terms of multiobjective optimization issues, because the goals in the global analysis of the process of the weight are different, it is necessary to improve the traditional Taguchi method. Entropy theory is used primarily to measure the impact of an evaluation of a certain index on the evaluation object. Thus, entropy theory is used to determine the weight of each target, and then the weight value is used to correct and improve the traditional Taguchi process capability index function and to establish a goal optimization function; once again, the generalized simple gradient is used to optimize the objective function.

3.1. Establishment of the Physical and Mechanical Performance Evaluation Index Weight of a Cold Rolling Spline Based on Entropy Theory. There are $n$ evaluation level combinations and $m$ evaluation indices. The test results are used to establish the evaluation matrix given in

$$
D_{m \times n}=\left[\begin{array}{cccc}
d_{11} & d_{12} & \cdots & d_{1 n} \\
d_{21} & d_{22} & \cdots & d_{2 n} \\
\vdots & \vdots & \vdots & \vdots \\
d_{m 1} & d_{m 2} & \cdots & d_{m n}
\end{array}\right] .
$$

Among the variables, $d_{m n}$ represents each response value.

In the spline cold roll-beating forming test data, because the evaluations of the cold roll-beating spline surface physical and mechanical properties of the two indicators of the numerical range and units are different, the objective direction of each evaluation index is also different; as a result, the Taguchi algorithm is used to obtain the signal-to-noise ratio of each evaluation index, and then the calibration parameters 
TABLE 6: Cold roll-beating spline entropy weight.

\begin{tabular}{lcc}
\hline Index & $\begin{array}{c}\text { Work-hardening } \\
\text { degree }\end{array}$ & $\begin{array}{c}\text { Residual } \\
\text { stress }\end{array}$ \\
\hline Entropy $\left(H_{i}\right)$ & 0.999943 & 0.999952 \\
Entropy weight $\left(w_{i}\right)$ & 0.5421 & 0.4579 \\
Subjective entropy weight $\left(\tau_{i}\right)$ & 0.60000 & 0.40000 \\
Integrated entropy weight $\left(W_{i}\right)$ & 0.6397 & 0.3603 \\
\hline
\end{tabular}

of the cold roll-beating spline evaluation matrix are used to standardize the standard matrix $X_{2 \times 25}$, as shown in

$$
X_{2 \times 25}=\left[\begin{array}{llll}
42.982 & 43.128 & \cdots & 43.419 \\
36.576 & 37.231 & \cdots & 38.910
\end{array}\right] .
$$

To characterize the cold roll-beating spline in production and processing and in comprehensive consideration of practical applications, the subjective entropy weight of the hardening degree and residual stress of the surface layer is determined using the cold roll-beating spline surface hardening specification matrix formula (9). According to (10), the subjective entropy weight is modified, and the synthesized entropy weight is obtained, as shown in Table 6.

$$
\begin{aligned}
L_{i j} & =\frac{X_{i j}}{\sum_{j=1}^{n} X_{i j}} \\
H_{i} & =\frac{-1}{\ln N} \sum_{j=1}^{n} L_{i j} \ln L_{i j} \\
w_{i} & =\frac{1-H_{i}}{m-\sum_{i=1}^{m} H_{i}} \\
W_{i} & =\frac{\tau_{i} w_{i}}{\sum_{i=1}^{m} \tau_{i} w_{i}} .
\end{aligned}
$$

In the formula, $L_{i j}$ is the proportion of the $i$ th index under the $j$ th test; $H_{i}$ is the entropy of the $i$ th evaluation index; $w_{i}$ is the entropy weight of the $i$ th evaluation index, also known as the objective entropy weight; $\tau_{i}$ is the subjective entropy weight; and $W_{i}$ is the subjective and objective entropy weight; among them, $L_{i j} \in[0,1], H_{i} \in[0,1], w_{i} \in[0,1]$, and $\sum_{i=1}^{m} w_{i}=1$ for $i=1,2,3, \ldots, m$.

3.2. Optimization of the Traceability Function of Taguchi Process Capability for the Physical and Mechanical Properties of the Cold Roll-Beating Spline Surface. The Taguchi process capability index can be considered an extension of the mean square error. The optimal level combination of each response value to the target is obtained in the case where the response variance is small; this approach is preferred for situations with target values and upper and lower tolerance lines [2527]. Therefore, the evaluation index of the physical and mechanical properties of the cold roll-beating spline surface is constructed using the Taguchi process capability index to construct the optimization function, as shown in

$$
\text { max: } \quad \text { Total } C_{\mathrm{pm}}=\left(D_{1} \cdot D_{2} \cdot D_{3} \cdots D_{i}\right)^{1 / i} .
$$

However, the influence of each evaluation index on the physical and mechanical properties of the finishing surface is different. Therefore, the entropy weight theory is used to correct and improve the traditional Taguchi process capability index optimization function of (11), as shown in

$$
\max : \quad \text { Total } C_{\mathrm{pm}}=D_{1}^{W_{1}} \cdot D_{2}^{W_{2}} \cdot D_{3}^{W_{3}} \cdots D_{i}^{W_{i}} \text {. }
$$

Here, $C_{\mathrm{pm}}$ is the total expected value of the process capability index; $W_{i}$ is the comprehensive entropy weight of each evaluation index; $D_{i}$ is the expected value of each evaluation index, where $i=2$; and the expected value $D_{i}$ of each evaluation index is calculated using

$$
D_{i}=\exp \left\{-k_{i} \cdot\left[\left(\bar{\gamma}_{i}-T_{i}\right)^{2}+\bar{\lambda}_{i}^{2}\right]\right\}
$$

As described elsewhere [26], the polynomial regression model in (14) is fitted with the cold roll-beating test data in Table 3, and the significance test results of each evaluation index fitting model are obtained; next, the fitting mean $\gamma_{i}$ and the fitting standard deviation $\lambda_{i}$ are obtained; $k_{i}$ is the loss factor [26].

$$
\begin{aligned}
R_{i}= & \beta_{0}+\beta_{1} n+\beta_{2} f+\beta_{3} r+\beta_{12} n f+\beta_{13} n r+\beta_{23} f r \\
& +\beta_{11} n^{2}+\beta_{22} f^{2}+\beta_{33} r^{2}+\beta_{123} n f r+\beta_{112} n^{2} f \\
& +\beta_{113} n^{2} r+\beta_{221} f^{2} n+\beta_{223} f^{2} r+\beta_{331} r^{2} n \\
& +\beta_{332} r^{2} f+\beta_{111} n^{3}+\beta_{222} f^{3}+\beta_{333} r^{3}+\varepsilon .
\end{aligned}
$$

In order to determine whether the regression model fitting degree is good or bad, the significance test and ANOVA results of (14) are shown in Tables 7 and 8.

From Tables 7 and 8 , the $P$ values of the two regression models are all below 0.0001 . The complex correlation coefficients of the model are $95.63 \%$ and $98.44 \%$, and it can be shown that the fitting result is reliable.

Because this cold roll-beating spline is used in agricultural equipment, the spline bears relatively large loads. Based on the actual working conditions of the failure and damage, we set the cold roll-beating spline surface workhardening capacity as $H_{v} \in[139.6 \%, 149.6 \%]$, the cold rollbeating spline surface residual stress as $\delta \in[-69.79,-88.21]$, the machining parameters to the cold roll-beating speed as $n \in[1200,2500]$, the feed speed as $f \in[20,50]$, and the roll-beating wheel round corner radius as $r \in[1,3.5]$. According to (12), we solve the spline surface hardening degree and residual stress process capability index. Next, the generalized simple gradient method is used to optimize the overall Taguchi process capability index. The traditional Taguchi optimization results and this paper's optimization results are summarized in Table 9.

Through the analysis of the optimization results in Table 9, from the perspective of overall process capability index, $C_{\mathrm{pm}}$ of the present method is bigger than $C_{\mathrm{pm}}$ of traditional Taguchi method, so the method used in this article is better than the other methods. The optimal processing technology parameters are determined as follows: cold rollbeating speed of $1574.5 \mathrm{r} / \mathrm{mm}$, feed speed of $43.21 \mathrm{~mm} / \mathrm{min}$, 
TABLE 7: Significant test of work-hardening degree regression model.

\begin{tabular}{|c|c|c|c|c|c|}
\hline Sources of variance & Sum of squares & Degrees of freedom & Complex correlation coefficient & $F$ value & $P$ value \\
\hline Regression & 0.013 & 9 & 0.9563 & 117.28 & $<0.0001$ \\
\hline Residual & $7.665 \times 10^{-5}$ & 6 & & & \\
\hline Total & 0.014 & 15 & & & \\
\hline
\end{tabular}

TABLE 8: Significant test of residual stress regression model.

\begin{tabular}{|c|c|c|c|c|c|}
\hline Sources of variance & Sum of squares & Degrees of freedom & Complex correlation coefficient & $F$ value & $P$ value \\
\hline Regression & 551.7982 & 5 & 0.9844 & 176.5416 & $<0.0001$ \\
\hline Residual & 8.7515 & 14 & & & \\
\hline Total & 560.5497 & 19 & & & \\
\hline
\end{tabular}

TABLE 9: Optimization results.

\begin{tabular}{|c|c|c|c|c|}
\hline & Evaluation index & Fitted mean & Fitting residual error & Total $C_{\mathrm{pm}}$ \\
\hline \multirow{2}{*}{ Traditional Taguchi method } & Work-hardening degree & 145.12 & 21.48 & \\
\hline & Residual stress & 79.72 & 34.328 & 1.802 \\
\hline \multirow{2}{*}{ Present method } & Work-hardening degree & 147.2 & 22.9048 & \\
\hline & Residual stress & 81.32 & 36.688 & 3.6241 \\
\hline
\end{tabular}

TABLE 10: Optimization results verification experiment configuration.

\begin{tabular}{lcccc}
\hline & $\begin{array}{c}\text { Experiment serial } \\
\text { number }\end{array}$ & Cold roll-beating speed & $\begin{array}{c}\text { Feeding speed } \\
\text { Roll-beating round } \\
\text { radius }\end{array}$ \\
\hline Optimization results experiment & I & 1581 & 42 & 2 \\
\hline & II & 1581 & 51 & 2 \\
Contrast validation experiment & III & 1581 & 35 & 2 \\
& IV & 1581 & 42 & 3 \\
& V & 1581 & 42 & 2 \\
\hline
\end{tabular}

and roll-beating wheel round corner radius of $2.06 \mathrm{~mm}$. Because the cold roll-beating processing uses a step speed change, the abovementioned cold roll-beating spline surface physical and mechanical performance optimization results are adjusted to a cold roll-beating speed of $1581 \mathrm{r} / \mathrm{mm}$, feed speed of $42 \mathrm{~mm} / \mathrm{min}$, and roll-beating wheel round corner radius of $2 \mathrm{~mm}$.

\section{Experimental Verification and Contrast Analysis of the Optimization Results of the Physical and Mechanical Properties of the Cold Roll-Beating Spline Surface}

From the above Taguchi signal-to-noise ratio analysis, the effect of the cold roll-beating parameters on the surface physical and mechanical properties can be ordered as follows: feeding speed $>$ roll-beating round radius $>$ cold roll-beating speed; therefore, according to the above optimization results, 7 groups of experiments are established, as shown in Table 10.
According to Table 10, we verify the experiment parameter set for each group of experiment selected spline split circles at the same location three times to measure the residual stress and microhardness values; the experiment results are shown in Figure 3. The microstructure of the circular surface of the spline was observed under 1000 electron microscopy images, as shown in Figure 4.

The results of the surface hardening and residual stress experiment of the spline index circle are shown in Figure 3. In Figure 3(a), the work-hardening degree of the Group II experimental results is larger than that of the Group I experimental results, but the difference is not large; the Group III experimental results are closer to those of the Group I experiment, with the results of the Group I experiment exhibiting greater work hardening than the other groups of experimental results. In Figure 3(b), the first experiment results of residual stress on all of Group I are larger than the results of the other groups of experiments; the Group I experimental results feature the second largest difference between two groups of experiment results, and relative to 


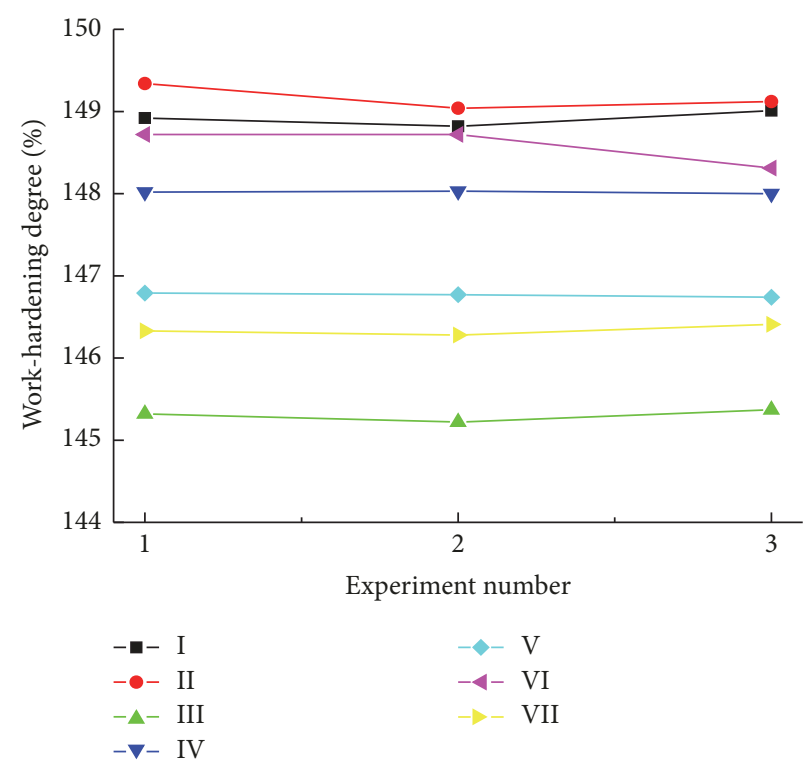

(a) Cold roll-beating spline indexing round hardening experiment results

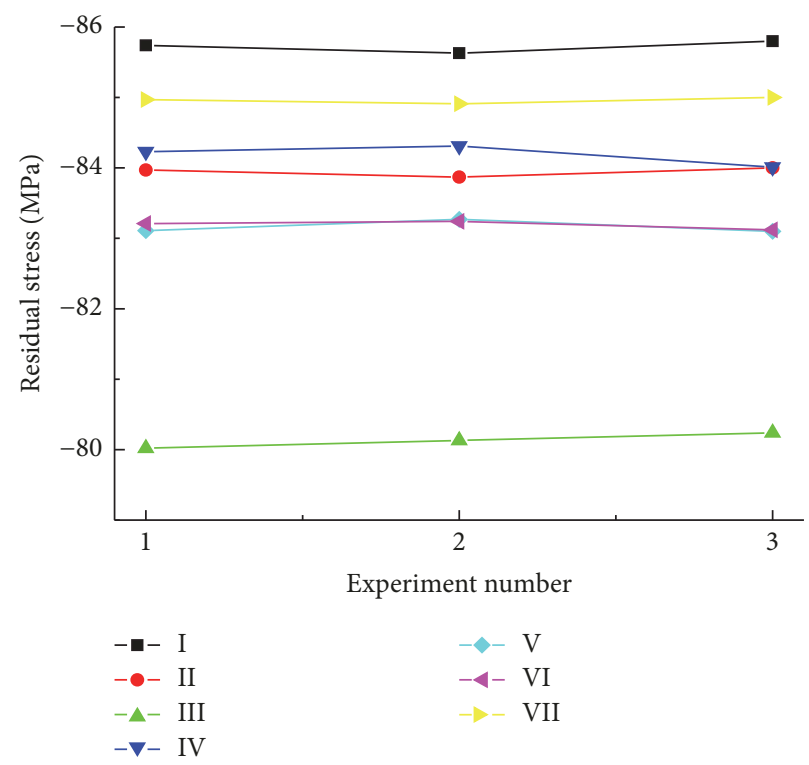

(b) Residual stress experiment results of the cold roll-beating spline circle

FIGURE 3: Cold roll-beating splash experimental results.

the experiment results of the Group III experiment, the difference is greater. Therefore, considering the influence of each experimental parameter on the physical and mechanical properties of the spline surface, we conclude that the first set of experiment parameters is better than those of the other groups; as a result, the Taguchi results are verified as reliable.

According to the surface microstructure morphology of the test spline index circle in Figure 4, a difference exists in the degree of change in the crystal structure of each group. Overall, in the first group of experiments, the crystal unevenness is higher, the crystals are stretched more significantly, the crystals and their inclusions are crushed, the degree of refinement of the other groups is more prominent, and the fiber tissue density is greater. As the degree of deformation of the spline and the density of the fiber directly affect the physical and mechanical properties of the spline surface, we conclude from the first group of tests that the degree of hardening and residual stress of the other groups is more significant, thereby establishing the accuracy of Taguchi process capability index optimization model.

\section{Conclusions}

By studying the forming experiment of spline cold rolling and the mirror scanning experiment, the experimental results of 


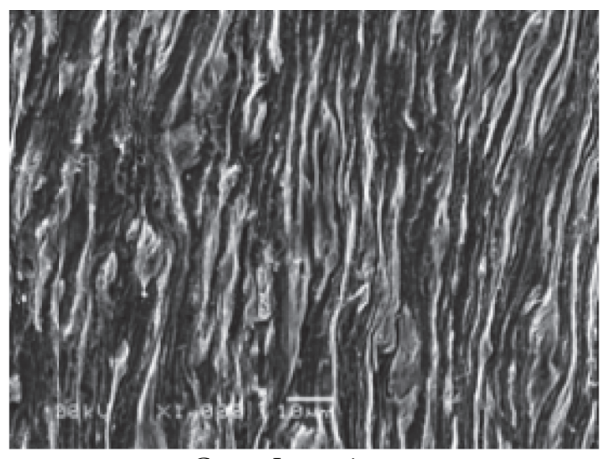

Group I experiment

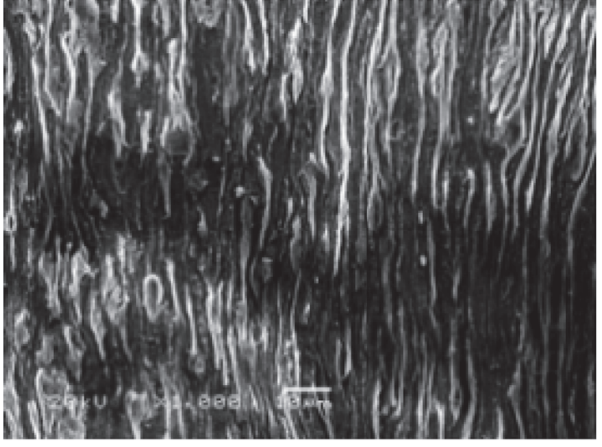

Group II experiment

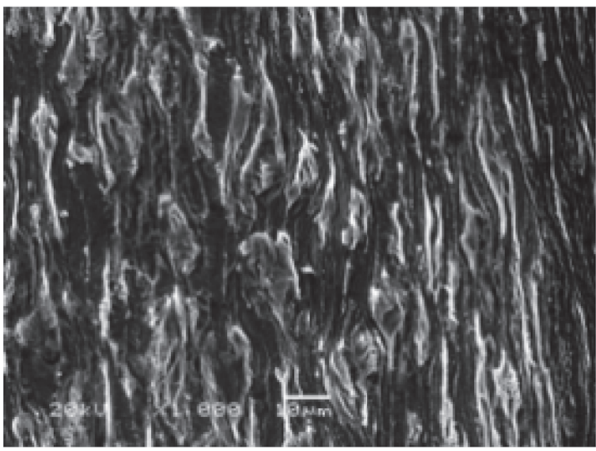

Group IV experiment

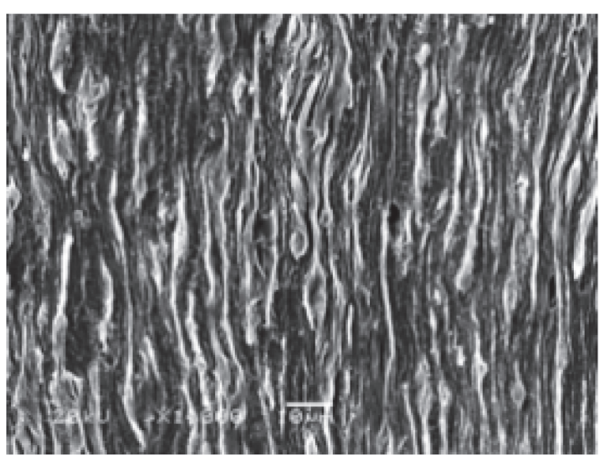

Group VI experiment

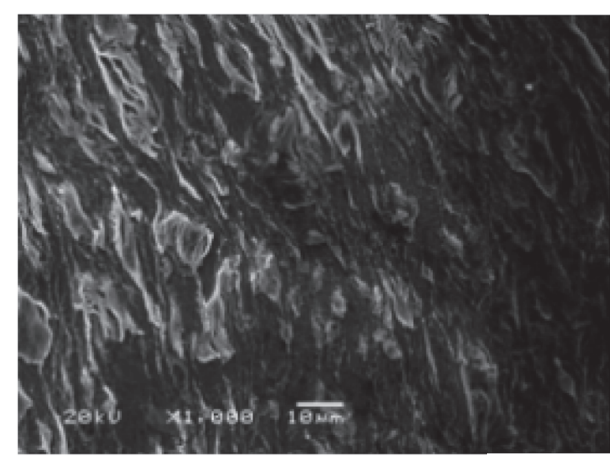

Group III experiment

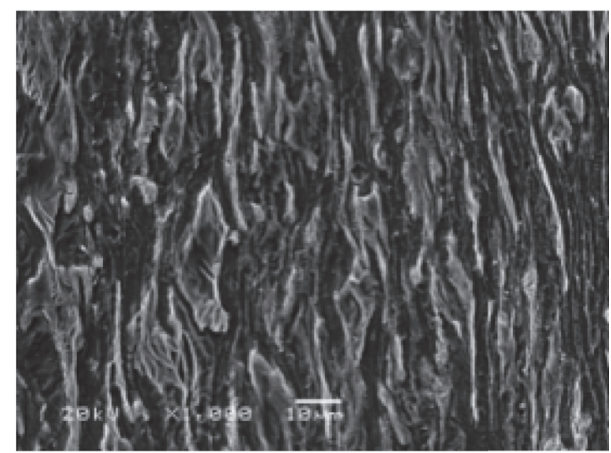

Group V experiment

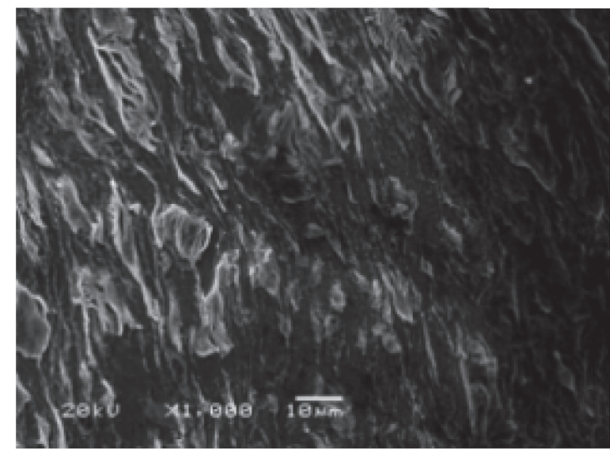

Group VII experiment

FIgURE 4: Microstructures of the surfaces of the spline index circle specimens. 
the physical and mechanical properties of the spline surface were analyzed using Taguchi theory; based on the results, the following conclusions were obtained:

(1) Taguchi theory indicates that the feed rate plays a leading role in the physical and mechanical properties of the spline surface and that the round corner radius has the second most important impact; the impact of the cold roll speed is minimal.

(2) Using the Taguchi process capability index to optimize the model, the optimal machining parameters are as follows: cold roll-beating speed of $1581 \mathrm{r} / \mathrm{mm}$, feed rate of $42 \mathrm{~mm} / \mathrm{min}$, and roll rounded radius of $2 \mathrm{~mm}$.

(3) By observing the spline tooth surface microstructure, Taguchi process capability index model optimization results at the spline indexing process at the surface layer of metal flow and grain refinement degree are more obvious than in the other groups, demonstrating that the optimization results are better in improving the physical and mechanical properties of the spline surface.

\section{Conflicts of Interest}

The authors declare that they have no conflicts of interest.

\section{Acknowledgments}

This project was sponsored by the National Natural Science Foundation of China (Grants nos. 51475146 and 51475366).

\section{References}

[1] F. Cui, X. Wang, F. Zhang, H. Xu, J. Quan, and Y. Li, "Metal flowing of involute spline cold roll-beating forming," Chinese Journal of Mechanical Engineering, vol. 26, no. 5, pp. 1056-1062, 2013.

[2] F. K. Cui, X. D. Dong, X. Q. Wang et al., "Experimental analysis of dynamic mechanical properties of 20 quenched and tempered steel for cold roll-beating," Materials Research Innovations, vol. 19, S1, pp. 56-61, 2015.

[3] L. Yan, L. Yuxi, Y. Mingshun, Y. Qilong, and C. Fengkui, "Analyzing the thermal mechanical coupling of 40Cr cold rollbeating forming process based on the Johnson-Cook dynamic constitutive equation," International Journal of Heat and Technology, vol. 33, no. 3, pp. 51-58, 2015.

[4] N. Kurz, "Theoretical and experimental investigations of the "Grob" cold shape-rolling procrss," in Proceedings of the 25th International Machine Tool Design and Research Conference, pp. 551-559, Birmingham, UK, 1985.

[5] Y. Mingshun, L. Yan, Z. Jianming et al., "Simulation and experiment research on deforming force of slab cold rollbeating," Sensors \& Transducers Journal, vol. 16, no. 1, pp. 285294, 2012.

[6] Y. Mingshun, L. Yan, Y. Qilong et al., "A hybrid method to deformation force of high-speed cold roll-beating forming," Journal of Digital Information Management, vol. 11, no. 2, pp. 146-153, 2013.
[7] F. K. Cui, Y. F. Ling, J. X. Xue, J. Liu, Y. Liu, and Y. Li, "Work hardening behavior of 1020 steel during cold-beating simulation," Chinese Journal of Mechanical Engineering, vol. 30, no. 2, pp. 321-331, 2017.

[8] L. Yan, Y. Mingshun, Y. Qilong, and Z. Jianming, "Study on the metal flowing of lead screw cold roll-beating forming," Advanced Science Letters, vol. 4, no. 6-7, pp. 1918-1922, 2011.

[9] Z. H. Ding, F. K. Cui, Y. B. Liu, Y. Li, and K. G. Xie, "A model of surface residual stress distribution of cold rolling spline," Mathematical Problems in Engineering, vol. 2017, Article ID 2425645, 21 pages, 2017.

[10] N. Masmiati and A. A. D. Sarhan, "Optimizing cutting parameters in inclined end milling for minimum surface residual stress-Taguchi approach," Measurement, vol. 60, pp. 267-275, 2015.

[11] K. Palanikumar, "Application of Taguchi and response surface methodologies for surface roughness in machining glass fiber reinforced plastics by PCD tooling," The International Journal of Advanced Manufacturing Technology, vol. 36, no. 1-2, pp. 1927, 2008

[12] P. Rupajati, B. O. P. Soepangkat, B. Pramujati, and H. C. K. Agustin, "Optimization of recast layer thickness and surface roughness in the wire EDM process of AISI H13 tool steel using Taguchi and fuzzy logic," Applied Mechanics and Materials, vol. 493, pp. 529-534, 2014.

[13] W.-J. Chen, C.-C. Hsu, and Y.-L. Yang, "Improving roughness quality of end milling Al 7075-T6 alloy with Taguchi based multiobjective quantum behaved particle swarm optimisation algorithm," Materials Research Innovations, vol. 18, pp. S2647S2653, 2014.

[14] M. B. Prime, "Cross-sectional mapping of residual stresses by measuring the surface contour after a cut," Journal of Engineering Materials and Technology, vol. 123, no. 2, pp. 162-168, 2001.

[15] P. Pagliaro, M. B. Prime, J. S. Robinson et al., "Measuring inaccessible residual stresses using multiple methods and superposition," Experimental Mechanics, vol. 51, no. 7, pp. 1123-1134, 2011.

[16] C. Liu and X. Yi, "Residual stress measurement on AA6061-T6 aluminum alloy friction stir butt welds using contour method," Materials and Design, vol. 46, no. 4, pp. 366-371, 2013.

[17] L. Seifi, A. Torabian, H. Kazemian et al., "Adsorption of BTEX on surfactant modified granulated natural zeolite nanoparticles: parameters optimizing by applying taguchi experimental design method," Clean-Soil, Air, Water, vol. 39, no. 10, pp. 939-948, 2011.

[18] P. G. Benardos and G.-C. Vosniakos, "Prediction of surface roughness in $\mathrm{CNC}$ face milling using neural networks and Taguchi's design of experiments," Robotics and ComputerIntegrated Manufacturing, vol. 18, no. 5-6, pp. 343-354, 2002.

[19] S. R. Patel and Z. V. P. Murthy, "Optimization of process parameters by Taguchi method in the recovery of lactose from whey using sonocrystallization," Crystal Research and Technology, vol. 45, no. 7, pp. 747-752, 2010.

[20] F. U. Xialong, Processing Parameters Optimization of Auto Lens Based on Simulated Annealing Genetic Algorithm, Zhejiang University of Technology, 2013.

[21] W. Peng, Simulation of Forming Process and Optimization of Forming Process Parameters of Autombile Fender Based on Taguchi Algorithm, Anhui Polytechnic University, 2017.

[22] S. Miki, H. Okazawa, and H. Inujima, "Evaluation of the degree of deterioration of circuit-breaker insulators using chemical 
analysis and the Mahalanobis-Taguchi (MT) method," Electrical Engineering in Japan, vol. 168, no. 1, pp. 11-20, 2010.

[23] D. H. Cho and Y. Jeong, "Analysis of spinning process parameters on development of spun-dyea PET yarn using the Taguchi method," Journal of Applied Polymer Science, vol. 102, no. 2, pp. 1419-1427, 2006.

[24] T. Goyal, R. S. Walia, and T. S. Sidhu, "Surface roughness optimization of cold-sprayed coatings using Taguchi method," The International Journal of Advanced Manufacturing Technology, vol. 60, no. 5-8, pp. 611-623, 2012.

[25] P.-H. Lee and B.-J. Yum, "Multi-characteristics parameter design: A desirability function approach based on process capability indices," International Journal of Reliability, Quality and Safety Engineering, vol. 10, no. 4, pp. 445-461, 2003.

[26] F.-C. Wu, "Optimization of correlated multiple quality characteristics using desirability function," Quality Engineering, vol. 17, no. 1, pp. 119-126, 2005.

[27] F. J. Pontes, A. P. D. Paiva, P. P. Balestrassi, J. R. Ferreira, and M. B. D. Silva, "Optimization of Radial Basis Function neural network employed for prediction of surface roughness in hard turning process using Taguchi's orthogonal arrays," Expert Systems with Applications, vol. 39, no. 9, pp. 7776-7787, 2012. 


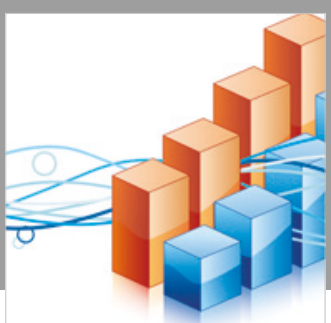

Advances in

Operations Research

\section{-n-m}
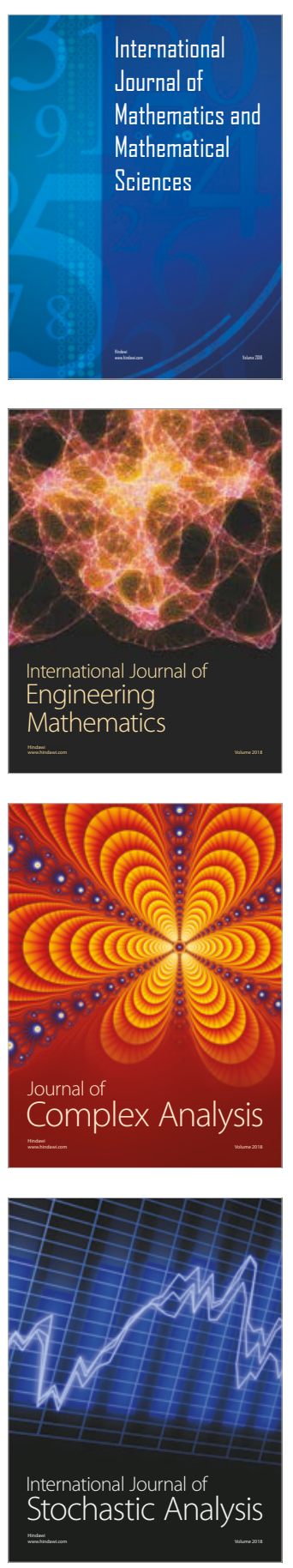
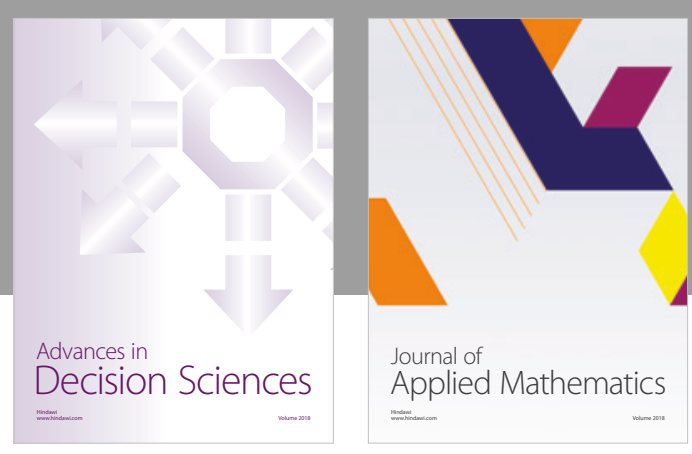

Journal of

Applied Mathematics
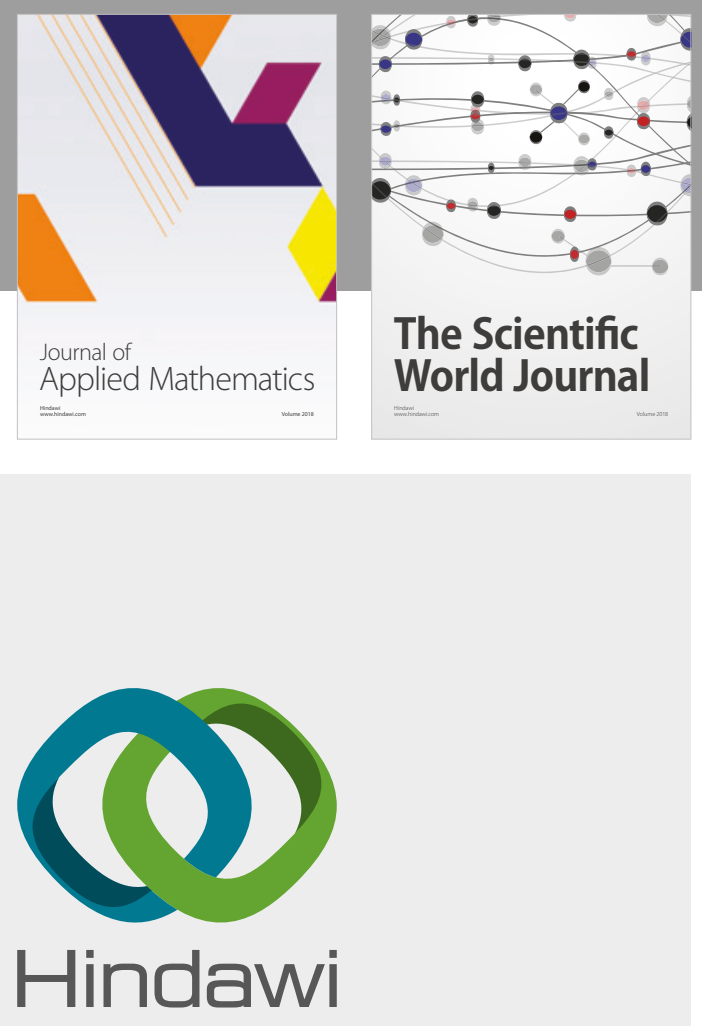

Submit your manuscripts at

www.hindawi.com

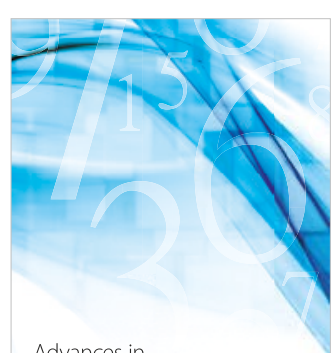

Advances in
Numerical Analysis
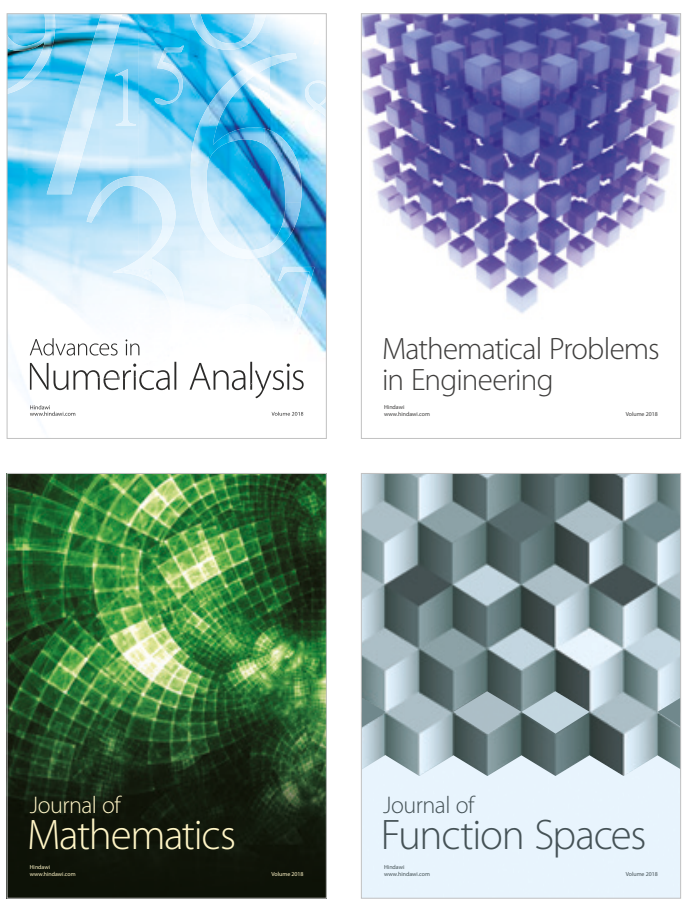

Mathematical Problems in Engineering

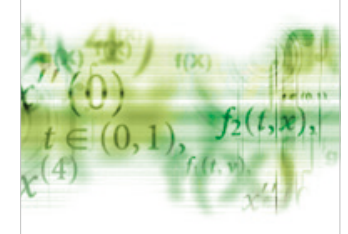

International Journal of

Differential Equations

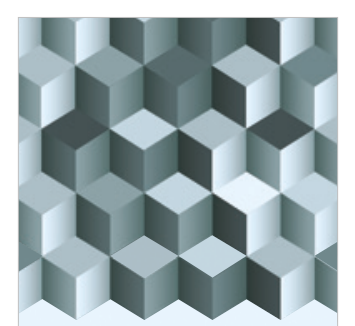

Journal of

Function Spaces

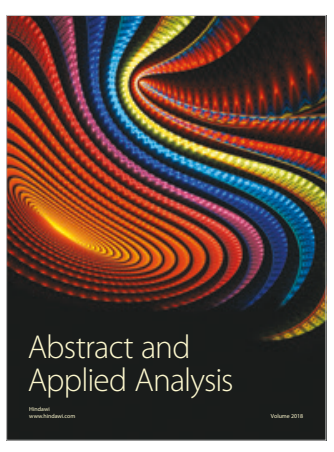

The Scientific

World Journal

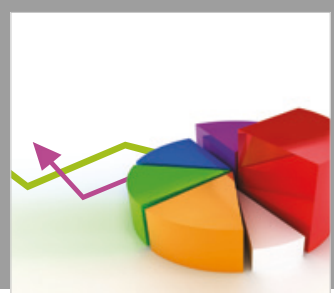

Journal of

Probability and Statistics
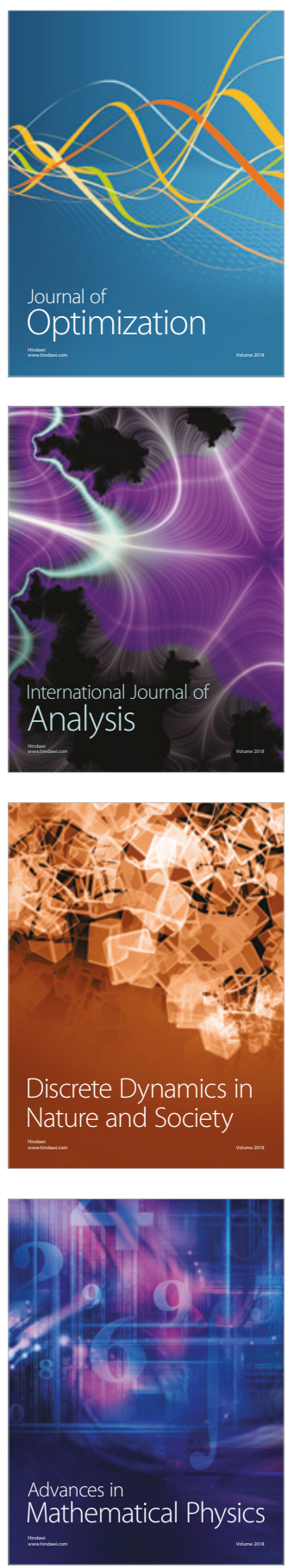